\title{
Spontaneous and radiation-induced chromosomal instability and persistence of chromosome aberrations after radiotherapy in lymphocytes from prostate cancer patients
}

\author{
Andrea Hille · Hana Hofman-Hüther • \\ Elna Kühnle · Barbara Wilken · Margret Rave-Fränk • \\ Heinz Schmidberger · Patricia Virsik
}

Received: 11 May 2009/Accepted: 1 September 2009/Published online: 18 September 2009

(C) The Author(s) 2009. This article is published with open access at Springerlink.com

\begin{abstract}
The aim of the study was to compare the spontaneous and ex vivo radiation-induced chromosomal damage in lymphocytes of untreated prostate cancer patients and age-matched healthy donors, and to evaluate the chromosomal damage, induced by radiotherapy, and its persistence. Blood samples from 102 prostate cancer patients were obtained before radiotherapy to investigate the excess acentric fragments and dicentric chromosomes. In addition, in a subgroup of ten patients, simple exchanges in chromosomes 2 and 4 were evaluated by fluorescent in situ hybridization (FISH), before the onset of therapy, in the middle and at the end of therapy, and 1 year later. Data were compared to blood samples from ten age-matched healthy donors. We found that spontaneous yields of acentric chromosome fragments and simple exchanges were significantly increased in lymphocytes of patients before onset of therapy, indicating chromosomal instability in these patients. Ex vivo radiation-induced aberrations were not significantly increased, indicating proficient repair of radiation-induced DNA double-strand breaks in lymphocytes of these patients. As expected, the yields of
\end{abstract}

\footnotetext{
A. Hille · H. Hofman-Hüther · E. Kühnle - B. Wilken ·

M. Rave-Fränk ( $\square)$

Abteilung für Strahlentherapie und Radioonkologie,

Universitätsmedizin Göttingen, Robert-Koch-Strasse 40,

37075 Göttingen, Germany

e-mail: mfraenk@med.uni-goettingen.de

P. Virsik

Abteilung für Umweltmedizin und Hygiene,

Universitätsmedizin Göttingen, Robert-Koch-str. 40,

37075 Göttingen, Germany

H. Schmidberger

Klinik und Poliklinik für Radioonkologie sowie

Strahlentherapie, Universitätsklinikum Mainz,

Langenbeck str. 1, 55131 Mainz, Germany
}

dicentric and acentric chromosomes, and the partial yields of simple exchanges, were increased after the onset of therapy. Surprisingly, yields after 1 year were comparable to those directly after radiotherapy, indicating persistence of chromosomal instability over this time. Our results indicate that prostate cancer patients are characterized by increased spontaneous chromosomal instability. This instability seems to result from defects other than a deficient repair of radiation-induced DNA double-strand breaks. Radiotherapy-induced chromosomal damage persists 1 year after treatment.

\section{Introduction}

Prostate cancer is the most frequent malignancy in US and European men, with increasing rates of incidence. Despite numerous studies, which identified many potential risk factors and suggested many hypotheses on the cause of prostate cancer, its aetiology remains unknown. Recent scientific and clinical evidence suggested an interplay of genetic susceptibility, predisposition to infection and impaired antioxidant defence in the genesis of prostate cancer (Klein et al. 2006).

It is widely accepted that cancer develops through the accumulation of genetic alterations in a variety of genes that are essential for cellular processes such as growth, proliferation, differentiation or programmed cell death, cellular repair and oxidative stress defence (Kim et al. 2006; Klein et al. 2006; Sandberg 1991; Trzeciak et al. 2004). Repair defects as well as defects in enzymatic antioxidative defence and/or repair of oxidative DNA damage may be related to chromosomal changes and may thus be revealed by cytogenetic means (Dayal et al. 2008; Solomon et al. 1991; Waters et al. 2007; Wright 1999). The 
most noticeable correlation between the presence of high level genomic/chromosomal instability and a predisposition to cancer has been established in rare cancer syndromes, namely in ataxia telangiectasia, Bloom's syndrome and Fanconi's anaemia. Low-level genomic instability is, however, present in peripheral blood lymphocytes of patients with a variety of cancer types, such as breast, skin, stomach, head and neck, and bladder cancers, testicular seminoma and lymphoma (Barrios et al. 1988, 1990; Bhatti et al. 2008a; Bonassi et al. 1995, 2008; Colleu-Durel et al. 2004; De Ruyck et al. 2008; Hagmar et al. 1994, 1998; Madhavi et al. 1990; Nordenson et al. 1984; Rossner et al. 2005; Schabath et al. 2003; Schmidberger et al. 2001; Sigurdson et al. 2005; Smith et al. 2003).

Prostate cancer is a multifactor disease, the development of which involves genomic instability. Although there are numerous reports in literature on prostate cancer, there is little information regarding the spontaneous background levels of chromosomal alterations in these patients (De Ruyck et al. 2008; Dotan et al. 2004; El-Zein et al. 2005; Ozen et al. 2000; Steiner et al. 2002; Varga et al. 2005; Verhagen et al. 2002; Wolter et al. 2002). Varga et al. reported that spontaneous, as well as radiation-induced, micronuclei were not increased in sporadic prostate cancer patients compared to healthy male controls. Interestingly, they also analysed the frequently postulated age dependence of spontaneous aberration frequencies and found no differences, within the patient group (22 patients, 5475 years old) as well as in the control group (43 men, 2677 years old) (Varga et al. 2005).

On the other hand, an increased frequency of chromosome aberrations in circulating lymphocytes is often considered indicative of increased cancer risk after exposure to DNA-damaging agents, such as irradiation (Barrios et al. 1991; Bonassi et al. 2000; El-Zein et al. 2005; Hagmar et al. 1998; Heng et al. 2006; Hsu 1983; Kolusayin Ozar and Orta 2005; Lockett et al. 2006; Scott et al. 1999; Tzancheva and Komitowski 1997).

To address both issues, spontaneous and radiationinducible chromosomal instability, we conducted a study, including 102 patients with prostate cancer. We investigated whether these patients exhibited increased spontaneous chromosomal instability, and/or increased sensitivity against ionizing radiation, which could account for their susceptibility to cancer.

\section{Patients, materials and methods}

\section{Patients}

The present study was based on the analysis of chromosome aberrations observed in peripheral blood lymphocytes obtained from untreated and radiotherapy-treated prostate cancer patients and healthy donors.

During the first part of this study, 102 patients with previously untreated prostate cancer, registered at the Department of Radiotherapy and Radiooncology, University Medicine of Göttingen, participated in this study. Their tumours were classified according to the TNM system and only patients with primary tumours classified as T1-T3, $\mathrm{N} 0-\mathrm{N} 1$ and M0 were included in the study. Their median age was 69 years, and this group contained 66 lifelong nonsmokers, i.e. $72 \%$. For comparison, ten healthy male donors with matched ages participated in this part of the study. Their median age was 67 years, and this control group contained eight non-smokers, i.e. $80 \%$.

During the second part of this study, ten randomly chosen patients from the study group were included in the follow-up study. These patients were 62-79 years old, with a median age of 73 years; all patients were non-smokers. These patients were followed up during and after the therapy. Blood samples from these patients were obtained during therapy, at the end of therapy and 1 year after therapy (see also Table 1).

The Ethics Committee of the Medical Faculty, University of Göttingen, approved the study. All patients and healthy donors provided their informed consent before participating in the study.

\section{Lymphocyte cultures}

Heparinized peripheral blood samples were obtained by venipuncture from healthy donors and from untreated patients before therapy and from ten patients during therapy (after $50 \%$ of the dose fractions), immediately after and 1 year after therapy. Unirradiated or ex vivo irradiated whole blood lymphocytes ( $1 \mathrm{ml}$ per culture) were cultured in $9 \mathrm{ml} \mathrm{RPMI} \mathrm{containing} 10 \%$ foetal calf serum, $100 \mu \mathrm{l} / \mathrm{ml}$ PHA (Biochrom, Karlsruhe, Germany) and antibiotics $\left(10^{4}\right.$ I.E. $/ \mathrm{ml}$ penicillin and $10 \mathrm{mg} / \mathrm{ml}$ streptomycin) in $5 \% \mathrm{CO}_{2}$ atmosphere at $37^{\circ} \mathrm{C}$. To take into account individual variability and radiation-induced mitotic delay, all blood samples were divided and cultured for 46,48 and $50 \mathrm{~h}$, respectively. Colcemid $(20 \mu \mathrm{l} / \mathrm{ml}$ medium $)$ was added during the last two culture hours. Metaphase cells were prepared according to the standard method (hypotonic $0.56 \mathrm{M} \mathrm{KCl}$ treatment followed by fixation in methanol plus glacial acetic acid, $3: 1)$ and stored at $4^{\circ} \mathrm{C}$.

The optimal culture time for cell preparations containing no more than $6 \%$ of cells in their second postirradiation mitosis was chosen according to the results of foregoing evaluation based on FPG staining. This Giemsa-/Hoechst 33258-staining method allowed for differentiation between first and second post-irradiation metaphases. 
Table 1 Characteristics of ten healthy donors and ten study patients with prostate carcinoma followed during and after radiotherapy

\begin{tabular}{|c|c|c|c|c|c|}
\hline \multicolumn{2}{|c|}{ Healthy donors } & \multicolumn{4}{|l|}{ Patients } \\
\hline Number & Age (years) & Number & Age (years) & Tumour stage & $\begin{array}{l}\text { Percentage of irradiated } \\
\text { bone marrow volume }\end{array}$ \\
\hline 1 & 65 & 1 & 75 & T2b N1 M0 & 35 \\
\hline 2 & 69 & 2 & 79 & T1c N0 M0 & 17 \\
\hline 3 & 65 & 3 & 69 & T1c N0 M0 & 17 \\
\hline 4 & 64 & 4 & 76 & T1c N0 M0 & 17 \\
\hline 5 & 65 & 5 & 72 & T2c N0 M0 & 17 \\
\hline 6 & 65 & 6 & 71 & T1c N0 M0 & 17 \\
\hline 7 & 70 & 7 & 77 & T2c N0 M0 & 17 \\
\hline 8 & 81 & 8 & 66 & T2a N0 M0 & 17 \\
\hline 9 & 82 & 9 & 62 & T3a pN1 M0 & 35 \\
\hline 10 & 92 & 10 & 79 & T2b N0 M0 & 35 \\
\hline
\end{tabular}

Slides for evaluation of dicentric and acentric chromosomes were stained with $3 \%$ Giemsa solution (first part of this study). In unirradiated or irradiated lymphocytes, 100300 cells were scored per patient and healthy donor.

Slides for fluorescent in situ hybridization (FISH) were prepared and hybridized according to the MetaSystems protocol (MetaSystems, Altlussheim, Germany). Whole chromosome probes for chromosomes nos. 2 and 4 (dual paint FISH) were used simultaneously. Metaphase chromosomes were analysed with a fluorescent microscope (Zeiss Axioscop, Göttingen, Germany) equipped with a triple band pass filter for DAPI, Texas red and FITC, as well as with a CCD camera (Visitron Systems GmbH, Puchheim, Germany). MetaMorphR (West Chester, USA) software was used for image analysis. Complete and incomplete reciprocal translocations, dicentric chromosomes and complex exchanges involving either of the painted chromosomes were scored. The yields of dicentric chromosomes and reciprocal translocations were added up and classified as simple exchanges. For each patient and time (before, during and after therapy) and for each healthy donor, 250-950 cells were scored.

Ex vivo irradiation

Whole blood samples were irradiated at room temperature with $200 \mathrm{kV}$ X-rays and a dose of $D=3 \mathrm{~Gy}$. The radiation from an X-ray tube (Siemens Stabilipan, Erlangen, Germany) was filtered with $0.5 \mathrm{~mm}$ of $\mathrm{Cu}$.

Patient irradiation

All patients were treated in the primary treatment setting. Depending on tumour stage and risk factors (PSA > $20 \mathrm{ng}$ / $\mathrm{ml}$, Gleason-score $>7$ or positive lymph nodes), the prostate or the prostate and the pelvic nodes were treated. The dose administered was 71-72 Gy to the prostate and 45 Gy to the pelvis. The irradiation technique included individual optimization with conformal treatment planning, the use of multiple radiation fields, individual blocks, rectal balloons or (if possible) the prone position with a belly board, to reduce the small bowel volume within the planned target volume. External beam radiotherapy was given using a 20MV accelerator (Varian, Palo Alto, USA). Each field was irradiated daily, five times per week. The dose was specified according to the ICRU 50 recommendations (ICRU 1993). The exact radiotherapy technique has been described previously (Hille et al. 2005, 2008). Table 1 lists the individual characteristics of the ten patients, who were followed up during and after radiotherapy.

Statistical analysis

The overall aberration yields scored in lymphocytes from patients and healthy donors followed Poisson distribution as analysed by the test introduced by Brown and Zhao (2002). Therefore, the overall aberration yields in the patient group and in the healthy donors group were compared as two means of Poisson distributions using Student's $t$ test for infinite degrees of freedom, including the Yates correction factor. The groups comparing individual values were also tested by Wilcoxon and Mann and Whitney $U$ test, and completed by Siegel and Tukey rank dispersion test. Aberration yields in lymphocytes from patients before therapy and 1 year after the end of therapy were tested with these distribution-independent tests. $P$ values of $\leq 0.1$ were considered to be significant; the exact $P$ values are indicated in the text.

\section{Results}

The aberration yields in lymphocytes of 102 untreated prostate cancer patients were analysed in Giemsa-stained 
metaphase cells. For comparison, aberration yields of ten age-matched healthy donors were analysed, as well. In the patient and control groups, 12,120 and 2,200 cells were scored, respectively. Aberration yields per cell were calculated for dicentric chromosomes $\left(y_{\mathrm{dic}}\right)$ and for excess acentric fragments $\left(y_{\mathrm{ac}}(\mathrm{ex})\right)$. Data are presented in Fig. 1a, $\mathrm{b}$ as individual values, depending on age, and as box plots, with each box enclosing $50 \%$ of all collected data. The median values are displayed as horizontal lines within the corresponding boxes. Using Student's $t$ test for comparison of two means of Poisson distributions, we found that the yields of dicentric chromosomes per cell in patients and healthy donors were not significantly different $(P=0.4)$. The yields of excess acentric fragments were significantly different in these two groups $(P=0.05)$, with increased rates in the patient group. To determine whether aberration yields were affected by extension of the disease, we also compared patients with prostate only or with prostate and nodal disease. Using Student's $t$ test as described above, we found no significant differences $(P=0.4)$ between patients with prostate only or with prostate and nodal disease. Individual data are shown in Fig. 1a.

Next, we analysed aberration yields in Giemsa-stained lymphocytes from the same 102 untreated patients and healthy donors irradiated ex vivo with $200 \mathrm{kV}$ X-rays and a dose $D=3 \mathrm{~Gy}$. In the patient and control groups, 16,000 and 2,600 cells, respectively, were scored in Giemsastained metaphases. These data are presented in Fig. 2 as box plots, each box enclosing $50 \%$ of all collected data. The median values are displayed as horizontal lines within the corresponding boxes. Using Student's $t$ test for comparison of two means of Poisson distributions, we found that the yields of dicentric chromosomes per cell and those of excess acentric fragments per cell, as compared in patients and healthy donors, were not significantly different. Thus, in the studied prostate cancer patients, only spontaneous chromosomal instability could be revealed. Radiation-induced chromosomal instability, which would indicate an impaired repair of DNA double-strand breaks, was not observed.

To further analyse the spontaneous chromosomal instability found in prostate cancer patients, we applied dualcolour FISH method to lymphocytes and evaluated yields of simple exchanges $\left(y_{\mathrm{SE}}\right)$ in 10 out of 102 untreated patients and in the above 10 healthy donors. In these ten patients, we also studied the amplitude and persistence of aberrations as they were induced by conformal radiotherapy. In this smaller patient group, we analysed Giemsastained as well as FISH-stained lymphocyte metaphases. Spontaneous and radiation-induced $(D=3 \mathrm{~Gy})$ yields of simple exchanges in untreated patients and healthy donors, as well as the yields in patients during, immediately after
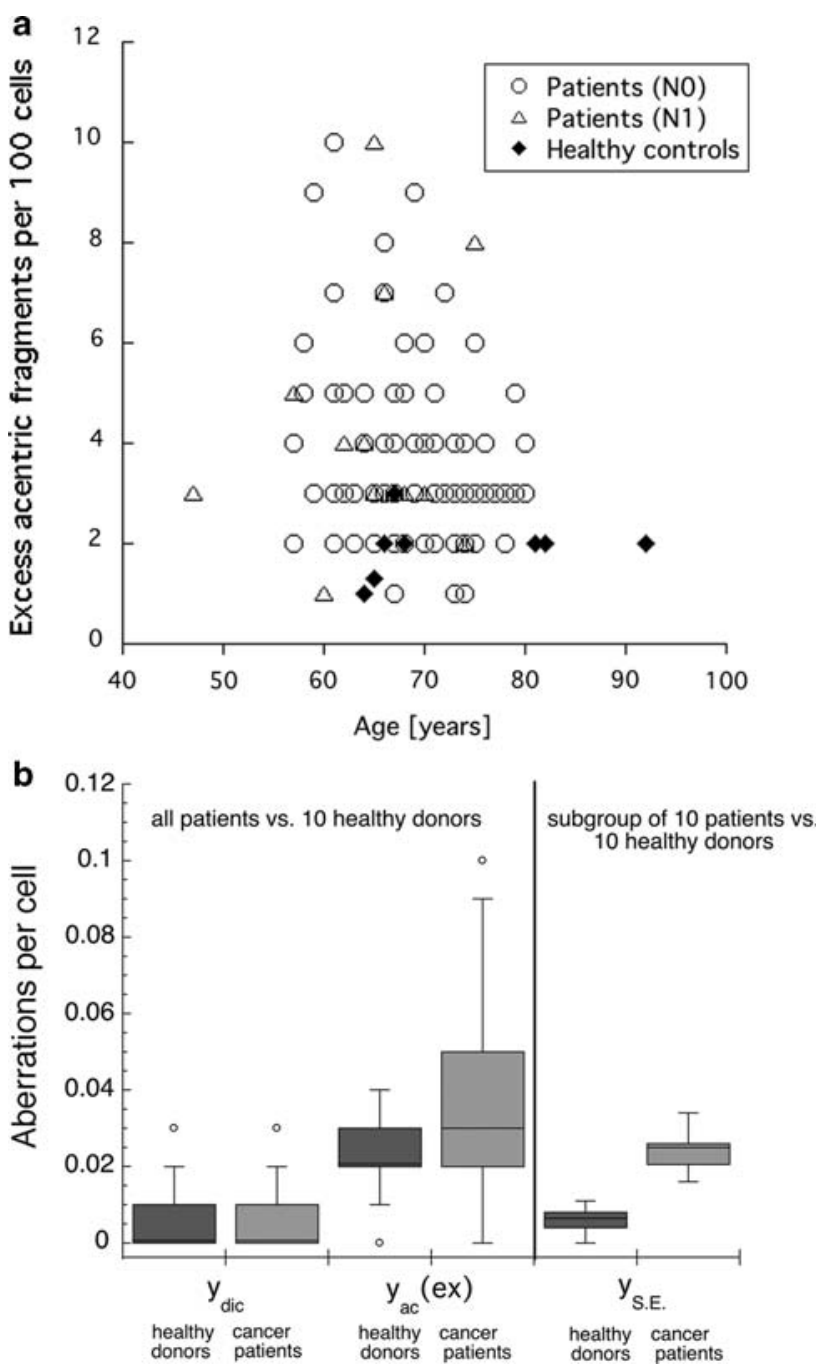

Fig. 1 a Spontaneous yields of excess acentric fragments per 100 cells (peripheral lymphocytes) in prostate cancer patients compared to healthy donors. Prostate cancers patients are divided into patients with prostate only (open circles) and patients with prostate and nodal disease (open triangles). Yields of excess acentric fragments $\left(y_{\mathrm{ac}}(\mathrm{ex})\right)$ were determined in Giemsa-stained metaphases. Data are presented as individual data points plotted depending on age (open symbols $=$ patients; closed diamonds $=$ healthy donors). b Spontaneous yields of chromosome aberrations per cell (peripheral lymphocytes) in prostate cancer patients compared to healthy donors. Yields of dicentric chromosomes $\left(y_{\text {dic }}\right)$ and excess acentric fragments $\left(y_{\mathrm{ac}}(\mathrm{ex})\right)$ were determined in Giemsa-stained metaphases. Yields of simple exchanges $\left(y_{\mathrm{SE}}\right)$, representing sums of dicentric chromosomes and reciprocal translocations, were evaluated in metaphases with painted chromosomes 2 and 4. Data are presented as box plots with each box enclosing $50 \%$ of the overall data. The corresponding median value of the variable is displayed as a horizontal line. The top and the bottom of the box mark the limits of $\pm 25 \%$ of the variable population. The vertical lines extending from the top and bottom of each box denote the minimum and maximum values within the data set that are located within an acceptable range (points with values either greater than the upper quartile $+1.5 x$ interquartile distance or less than lower quartile $-1.5 x$ interquartile distance); outliers that are not included are represented by circles 


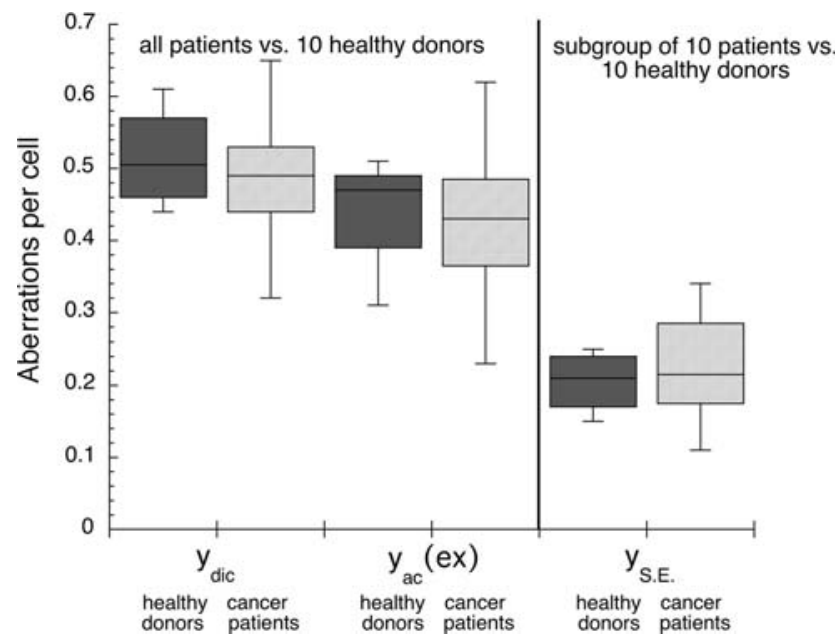

Fig. 2 Chromosome aberration yields per cell (peripheral lymphocytes) in prostate cancer patients compared to healthy donors after ex vivo irradiation with $D=3 \mathrm{~Gy}$. Blood samples of cancer patients were taken before radiotherapy. Yields of dicentric chromosomes $\left(y_{\text {dic }}\right)$ and excess acentric fragments $\left(y_{\mathrm{ac}}(\mathrm{ex})\right)$ were determined in Giemsa-stained metaphases. Yields of simple exchanges $\left(y_{\mathrm{SE}}\right)$, representing sums of dicentric chromosomes and reciprocal translocations were evaluated in metaphases with painted chromosomes 2 and 4. Data are presented as box plots with each box enclosing $50 \%$ of the overall data. Median value of the variable is displayed as a horizontal line. The top and the bottom of the box mark the limits of $\pm 25 \%$ of the variable population. The lines extending from the top and bottom of each box denote the minimum and maximum values within the data set that are located within an acceptable range (points with values either greater than the upper quartile $+1.5 x$ interquartile distance or less than lower quartile $-1.5 x$ interquartile distance); outliers that are not included are represented by circles

and 1 year after therapy were scored in metaphase cells. Spontaneous and radiation-induced yields of simple exchanges observed in chromosomes 2 and 4 are included in Figs. 1b and 2, respectively. Using Student's $t$ test for comparison of two means of Poisson distributions, we found that the yields of spontaneous simple exchanges in lymphocytes from untreated patients were significantly higher in comparison to healthy donors $(P=0.10)$. Again, in agreement with Giemsa-analysis, no significant difference $(P=0.70)$ was observed in lymphocytes irradiated ex vivo with $D=3 \mathrm{~Gy}$, as evaluated in the patient and control groups.

Both Giemsa and FISH results, when compared in prostate cancer patients and healthy donors, indicate that in these patients, the spontaneous, but not the radiationinduced, frequencies of simple exchanges (reciprocal translocations actually since dicentric yields were not different in both groups) and of excess acentric fragments are significantly increased. The increased spontaneous aberration frequencies are thus likely to arise from primary DNA damage that is different from DNA double-strand breaks, otherwise significant differences were observed between radiation-induced aberration frequencies too. Each one of the ten patients included in the FISH analysis showed increased spontaneous yields of simple exchanges per cell when compared with healthy donors. The corresponding single data are shown in Table 2.

During the follow-up of the patient subgroup, which displayed an increased spontaneous rate of chromosomal aberrations, blood samples were obtained during the therapy (after $50 \%$ of the fractions), immediately after and 1 year after therapy. Aberration yields were scored in Giemsa-stained and FISH-stained metaphases. Summarized data of this follow-up, i.e. yields of dicentrics, yields of excess acentric fragments and of simple exchanges are shown in Table 3. Using Giemsa-stain, 100-400 metaphase cells were scored for each point. For FISH-analysis, 200960 cells were scored for each point.

Time dependence of the aberration yields is shown in Fig. 3a-c, where the data are presented as box plots, each box enclosing $50 \%$ of all data. The median values are displayed as horizontal lines within the corresponding boxes. As can be seen in Fig. 3a-c, all types of aberrations persisted during the first year after the end of therapy. The yields observed immediately after the end of therapy were not significantly different from the yields observed 1 year after therapy (Wilcoxon, Mann and Whitney $U$ test, completed by Siegel and Tukey rank dispersion test, $P=0.05$ ).

\section{Discussion}

Mechanistic evidence supporting the role of chromosomal alterations in the development of cancer has been available for a long time, and epidemiological data showed that various markers of DNA repair (Berwick and Vineis 2000) or especially the frequency of chromosomal aberrations in

Table 2 Simple exchanges per cell in chromosomes nos. 2 and 4 in lymphocytes from prostate cancer patients and age-matched healthy donors

\begin{tabular}{lllllll}
\hline \multicolumn{2}{l}{ Healthy donors } & & & \multicolumn{2}{l}{ Patients } \\
\cline { 1 - 3 } \cline { 6 - 7 } Number & $N$ & $y_{\text {SE }}$ per cell & & Number & $N$ & $y_{\text {SE }}$ per cell \\
\hline 1 & 851 & 0.007 & & 1 & 582 & 0.024 \\
2 & 959 & 0.011 & & 2 & 618 & 0.034 \\
3 & 963 & 0.008 & & 3 & 541 & 0.019 \\
4 & 966 & 0.005 & & 4 & 508 & 0.016 \\
5 & 264 & 0.008 & & 5 & 805 & 0.022 \\
6 & 284 & 0.007 & & 6 & 733 & 0.021 \\
7 & 527 & 0.009 & & 7 & 873 & 0.026 \\
8 & 487 & 0.006 & & 8 & 869 & 0.026 \\
9 & 552 & 0.002 & & 9 & 844 & 0.026 \\
10 & 242 & 0.000 & & 10 & 809 & 0.026 \\
\hline
\end{tabular}


Table 3 Aberration yields $y_{\text {dic, }} y_{\mathrm{ac}}(\mathrm{ex})$ and $y_{\mathrm{SE}}$ scored before, in the middle and at the end of therapy and 1 year after therapy in lymphocytes from ten prostate cancer patients who received conformal radiotherapy

\begin{tabular}{|c|c|c|c|c|c|c|c|c|c|c|c|c|}
\hline \multirow[t]{2}{*}{ Patient number } & \multicolumn{3}{|c|}{ Before therapy } & \multicolumn{3}{|c|}{ Middle of therapy } & \multicolumn{3}{|c|}{ End of therapy } & \multicolumn{3}{|c|}{1 year after therapy } \\
\hline & $y_{\mathrm{dic}}$ & $y_{\mathrm{ac}}(\mathrm{ex})$ & $y_{\mathrm{SE}}$ & $y_{\mathrm{dic}}$ & $y_{\mathrm{ac}}(\mathrm{ex})$ & $y_{\mathrm{SE}}$ & $y_{\text {dic }}$ & $y_{\mathrm{ac}}(\mathrm{ex})$ & $y_{\mathrm{SE}}$ & $y_{\mathrm{dic}}$ & $y_{\mathrm{ac}}(\mathrm{ex})$ & $y_{\mathrm{SE}}$ \\
\hline 1 & 0.010 & 0 & 0.024 & 0.170 & 0.160 & 0.020 & 0.220 & 0.120 & 0.031 & 0.172 & 0.102 & 0.100 \\
\hline 2 & 0 & 0.010 & 0.034 & 0.290 & 0.120 & 0.049 & 0.440 & 0.290 & 0.071 & 0.143 & 0.143 & 0.084 \\
\hline 3 & 0.020 & 0.029 & 0.019 & 0.063 & 0.089 & 0.041 & 0.054 & 0.080 & 0.069 & 0.070 & 0.078 & 0.041 \\
\hline 4 & 0.010 & 0.019 & 0.016 & 0.070 & 0.070 & 0.010 & 0.144 & 0.098 & 0.051 & 0.098 & 0.098 & 0.060 \\
\hline 5 & 0.010 & 0.020 & 0.022 & 0.140 & 0.140 & 0.021 & 0.260 & 0.180 & 0.041 & 0.149 & 0.089 & 0.041 \\
\hline 6 & 0.020 & 0.048 & 0.021 & 0.090 & 0.050 & 0.011 & 0.090 & 0.070 & 0.020 & 0.070 & 0.070 & 0.022 \\
\hline 7 & 0.010 & 0.050 & 0.026 & 0.150 & 0.100 & 0.009 & 0.091 & 0.100 & 0.042 & n.m. & n.m. & n.m. \\
\hline 8 & 0 & 0.018 & 0.026 & 0.055 & 0.082 & 0.010 & 0.075 & 0.103 & 0.050 & 0.088 & 0.072 & 0.021 \\
\hline 9 & 0.010 & 0.020 & 0.026 & 0.098 & 0.083 & 0.019 & 0.070 & 0.100 & 0.031 & 0.069 & 0.088 & 0.019 \\
\hline 10 & 0 & 0.010 & 0.026 & 0.160 & 0.110 & 0.039 & 0.250 & 0.160 & 0.078 & 0.170 & 0.170 & 0.099 \\
\hline
\end{tabular}

peripheral lymphocytes might be an independent marker of cancer susceptibility (Bonassi et al. 2008).

In the present study, we analysed spontaneous and radiation-induced chromosomal aberrations in 102 patients with prostate cancer by Giemsa-staining and in a subgroup of 10 patients by the FISH technique. In Giemsa-stained metaphases, genomic yields of dicentric chromosomes and excess acentric fragments were evaluated separately. Whilst the spontaneous rate of dicentric chromosomes did not vary between the studied prostate cancer patients and healthy subjects, the rate of spontaneous excess acentric fragments was significantly increased in the patient group. This finding is similar to the results reported for breast cancer (e.g. Baeyens et al. 2002; Varga et al. 2006). Of course, it must be taken into account, that our age-matched healthy donor group was much smaller than the patient group. It is a problem to obtain many healthy donors at this age with normal PSA values. For the same reason, the smoking status was different between the patient and the control group. The influence of smoking on the yields of chromosomal aberrations in blood lymphocytes is controversially discussed; in our study; we found no significant differences between the smoker and the non-smoker groups $(P \leq 0.05)$. Overall, our healthy control group was well age-matched and, therefore, our data indicate that a subgroup of prostate cancer patients with significantly increased chromosomal instability might exist. Further studies involving a larger healthy donor group are necessary.

Partial yields of simple exchanges were evaluated by means of whole chromosome painting involving chromosomes nos. 2 and 4. Their spontaneous rates were significantly increased in ten patients, as well. These results are similar to data published by El-Zein et al. (2005), who also examined spontaneous chromosome instability in prostate cancer patients and healthy controls. They used short-term lymphocyte cultures and evaluated chromosomal instability using fluorescence in situ hybridization assay with two probes targeting specific regions on chromosome $\mathrm{X}$ and chromosome 1. For both chromosomes, their results showed a significantly higher mean level of spontaneous breaks indicating that spontaneous chromosome instability could be a risk factor for prostate cancer.

In contrast, Lockett et al. (2006), using the alkaline Comet assay to evaluate whether basal DNA damage was associated with prostate cancer risk, found no differences between cases and controls. The difference in the results of the study by El-Zein et al. the present study and the study of Lockett et al. may be due to differences in the applied methods and the analysed end points.

With respect to radiation-induced chromosomal aberrations, in the present study we found no differences between patients and healthy subjects. Genomic yields of dicentric chromosomes and excess acentric fragments, and partial yields of simple exchanges involving chromosomes nos. 2 and 4 (ten patients) were analysed in blood samples taken before cancer treatment and irradiated with a dose of $3 \mathrm{~Gy}$ ex vivo. This is in contrast to studies analysing blood samples of patients with other tumour types, including breast, colon (Baria et al. 2001) and head-and-neck cancer (De Ruyck et al. 2008). The relationship between increased rates of radiation-induced chromosome aberrations in peripheral lymphocytes and a predisposition to cancer is based on the assumption that any deficiencies in the DNA repair system maintaining the integrity of the genome are likely to enable the development of cancer. Depending on the type of the induced lesion, different repair mechanisms will be activated. DNA double-strand breaks are a hallmark of ionizing radiation effects, which will activate specific repair pathways, mainly homologous recombination and nonhomologous end joining. Since we found no increased 

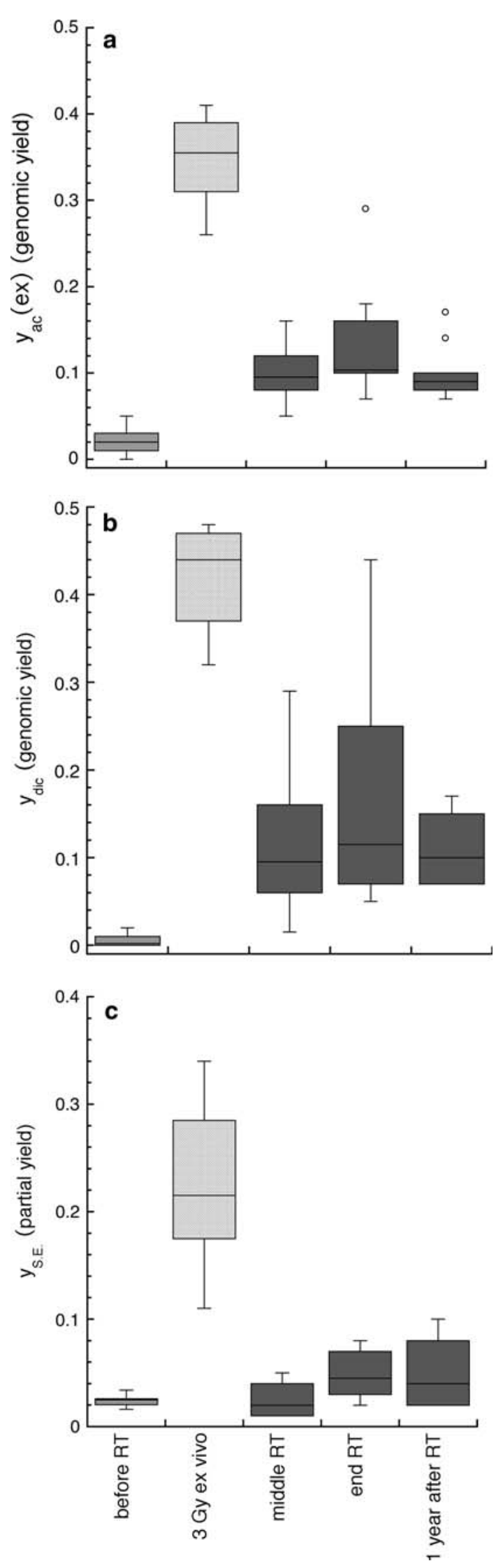

Fig. 3 a-c Genomic yields of excess acentric fragments (a), dicentric chromosomes (b), and partial yields of simple exchanges (c) per cell as observed at different times in peripheral lymphocytes of prostate cancer patients. Genomic aberration yields were determined in Giemsa-stained metaphases; partial yields of simple exchanges (dicentric chromosomes plus reciprocal translocations) were evaluated in metaphases with painted chromosomes 2 and 4. Blood samples of cancer patients were obtained before radiotherapy, in the middle and at the end of the treatment, as well as 1 year after treatment. Blood samples, obtained before treatment, were irradiated ex vivo with $D=3$ Gy. Data are presented as box plots with each box enclosing $50 \%$ of the data, and the median value of the variable displayed as a horizontal line. The top and the bottom of the box mark the limits of $\pm 25 \%$ of the variable population. The vertical lines extending from the top and bottom of each box denote the minimum and maximum values within the data set located within an acceptable range (points whose values is either greater than upper quartile $+1.5 x$ interquartile distance or less than lower quartile $-1.5 x$ interquartile distance); outliers that are not included are represented by circles

rates of radiation-induced chromosomal aberrations in patients with prostate cancer, defects in DNA doublestrand break repair pathways might not to be expected for these patients. Of course, this observation should be confirmed in studies involving a larger healthy donor group.

Increased production of reactive oxygen species, as often observed in cancer cells (Jackson and Loeb 2001) in association with an impaired cellular antioxidative defence (Nohmi et al. 2005; Trzeciak et al. 2004), will result in oxidative stress. Increased oxidative stress might promote tumour development as well (Dayal et al. 2008; Kim et al. 2006; Laurent et al. 2005; Rozalski et al. 2002; Tulard et al. 2003). In particular, the association between prostate cancer risk and an increased oxidative stress is widely accepted (Frohlich et al. 2008; Klein et al. 2006).

In the present study, we found that only spontaneous rates of excess acentric fragments and simple translocations (in ten patients) were significantly increased in patients with prostate cancer. In contrast to dicentric chromosomes and translocations, which typically arise from radiation-induced double-strand breaks, acentric fragments, detected also as micronuclei, may be generated by reactive oxygen species via oxidative base damage (Mateuca et al. 2008). Micronuclei contain predominantly acentric chromosomes or chromatid fragments. Increased spontaneous frequency of micronuclei in lymphocytes of untreated cancer patients has been already reported (Fenech 2002; Iarmarcovai et al. 2008).

The most frequent oxidative DNA damage is that in the 7, 8- dihydro-8-oxoguanine (8-OHdG) DNA adduct. This lesion is removed mainly by human oxoguanine glycosylase1, hOGG1, a glycosylase belonging to the group of prostate cancer susceptibility genes (Klein et al. 2006). In patients suffering from bone metastasis of their primary 
tumours, Rozalski et al. (2002) observed an about 50\% higher amount of $8-\mathrm{OHdG}$ excreted into the urine, as compared to healthy donors. It is generally accepted that the products of the $8-\mathrm{OHdG}$ repair are excreted into urine without further metabolism (Suzuki et al. 1995). The presence of 8-OHdG in urine is assumed to represent the primary repair product of this oxidative DNA base damage (Dianov et al. 1998). The higher 8-OHdG level in cancer patients might be explained by a permanently increased oxidative stress in their cells and/or by a decreased repair of the oxidative DNA damage due to deficient functioning of the enzymes involved, e.g. hOGG1. Defective excision of oxidative DNA damage was reported in malignant prostate cancer cell lines (Fan et al. 2004). Reduced incision of $8-\mathrm{OHdG}$ was associated with reduced hOGG1 2a expression in mitochondrial extracts from prostate cancer cell lines PC-3 and DU-145, as compared to wild-type healthy cells (Trzeciak et al. 2004).

In ten patients (FISH analysis subgroup), also an increased spontaneous rate of simple translocations was found. This might reflect the same origin as in the case of acentric fragments (oxidative DNA damage), since in the process of damaged base excision secondary double-strand breaks may be formed as well. Moreover, hydrogen peroxide originating from the superoxide anion radical, which is produced permanently due to mitochondrial metabolism, can induce double-strand-breaks directly.

Taken together, our findings point towards a deficiency in primary antioxidative defence and/or a deficiency in the repair or processing of oxidative DNA damage in cells from patients with prostate cancer as a likely cause of the increased spontaneous cytogenetic damage found in these patients. The combined influence of other possible repair defects might be also involved, as already pointed out by Bristow et al. (2007) in their recent review on this topic. Repair defects, especially in the oxidative damage repair, in prostate cancer cells will be studied in a large patient cohort. A deficient coping with oxidative stress and/or oxidative DNA damage in prostate cancer cells would be of a valuable therapeutical significance, allowing for new combined chemo- and radiotherapy.

It has been argued that tumour burden might be a potentially important confounding factor in the measurement of DNA repair capacity in patients after tumour diagnosis (Berwick and Vineis 2000). Tumour burden might suppress or decrease DNA repair activity through high metabolic rate and excessive endogenously generated oxidative stress, which might affect lymphocytes and their repair values (Pero et al. 1990). However, a recent study, based on data of cancer incidence in the United States Radiological Technologists Health Study (Sigurdson et al. 2003), reported on no evidence for differences in DNA damage assessed before and after cancer diagnosis (Bhatti et al. 2008b). Furthermore, family and classic twin studies clearly indicated a genetic predisposition to mutagen sensitivity (Klein et al. 2006; Roberts et al. 1999; Wu et al. 2006, 2007). In the present study, chromosome aberrations were not affected by disease extension, as we found no significant differences between patients with prostate only or with prostate and nodal disease.

In the follow-up part of our study (Fig. 3a-c), we observed persisting rates of cytogenetic damage during the first year after radiotherapy. This is in contrast with findings in patients with other types of cancer, e.g. testicular seminoma (Muller et al. 2005; Schmidberger et al. 2001) where after 1 year post-therapy, the high rates of cytogenetic damage observed shortly after therapy declined strongly. Also in head-and-neck cancer patients, a strong decline of cytogenetic damage rate by about $50 \%$ was observed in patients' blood lymphocytes (Xuncla et al. 2008).

The different results of the follow-up in prostate cancer study might also reflect the involvement of oxidative stress and its deficient defence in these cells. Chronic oxidative stress has already been associated with genomic/chromosomal instability following exposure to ionizing radiation (Tulard et al. 2003). Dayal et al. (2008) reported recently that in genomically unstable cells induced by ionizing radiation, a threefold increase in steady-state levels of hydrogen peroxide was observed. Their results clearly demonstrated the causal relationship between persistent oxidative stress induced by ionizing radiation via hydrogen peroxide and genomically/chromosomally unstable cells observed many generations after radiation exposure. The increased rates of cytogenetic damage observed in patients' lymphocytes 1 year after therapy might then reflect on chromosomal instability induced in the bone marrow stem cells repopulating the peripheral lymphocyte pool at that time. A longer follow-up study is necessary to study the prolonged presence of the cytogenetic damage in prostate cancer patients and to possibly correlate late effects of radiation therapy with the observed instability.

Our study has some limitations due to the small sample size of the age-matched control group, and due to the small number of patients followed up during radiation treatment and 1 year afterwards. However, our main findings that impaired DNA repair is at least not the only reason for chromosomal instability before radiotherapy and that instability persists after radiotherapy are strongly supported by recent publications (Arsova-Sarafinovska et al. 2009; Khandrika et al. 2009), which provide evidence for the existence of imbalance in the oxidative stress/antioxidant status in prostate cancer.

Acknowledgments The authors thank Bundesministerium für Bildung und Forschung for the financial support of this study by Grant $02 \mathrm{~S} 8203$. 
Open Access This article is distributed under the terms of the Creative Commons Attribution Noncommercial License which permits any noncommercial use, distribution, and reproduction in any medium, provided the original author(s) and source are credited.

\section{References}

Arsova-Sarafinovska Z, Eken A, Matevska N, Erdem O, Sayal A, Savaser A, Banev S, Petrovski D, Dzikova S, Georgiev V, Sikole A, Ozgok Y, Suturkova L, Dimovski AJ, Aydin A (2009) Increased oxidative/nitrosative stress and decreased antioxidant enzyme activities in prostate cancer. Clin Biochem (Epub ahead of print)

Baeyens A, Thierens H, Claes K, Poppe B, Messiaen L, De Ridder L, Vral A (2002) Chromosomal radiosensitivity in breast cancer patients with a known or putative genetic predisposition. Br J Cancer 87:1379-1385

Baria K, Warren C, Roberts SA, West CM, Scott D (2001) Chromosomal radiosensitivity as a marker of predisposition to common cancers? Br J Cancer 84:892-896

Barrios L, Caballin MR, Miro R, Fuster C, Berrozpe G, Subias A, Batlle X, Egozcue J (1988) Chromosome abnormalities in peripheral blood lymphocytes from untreated Hodgkin's patients. A possible evidence for chromosome instability. Hum Genet 78:320-324

Barrios L, Miro R, Caballin MR, Fuster C, Guedea F, Subias A, Egozcue J (1990) Chromosome instability in bladder carcinoma patients. Cancer Genet Cytogenet 49:107-111

Barrios L, Caballin MR, Miro R, Fuster C, Guedea F, Subias A, Egozcue J (1991) Chromosomal instability in breast cancer patients. Hum Genet 88:39-41

Berwick M, Vineis P (2000) Markers of DNA repair and susceptibility to cancer in humans: an epidemiologic review. J Natl Cancer Inst 92:874-897

Bhatti P, Doody MM, Alexander BH, Yuenger J, Simon SL, Weinstock RM, Rosenstein M, Stovall M, Abend M, Preston DL, Pharoah P, Struewing JP, Sigurdson AJ (2008a) Breast cancer risk polymorphisms and interaction with ionizing radiation among U.S. radiologic technologists. Cancer Epidemiol Biomarkers Prev 17:2007-2011

Bhatti P, Sigurdson AJ, Thomas CB, Iwan A, Alexander BH, Kampa D, Bowen L, Doody MM, Jones IM (2008b) No evidence for differences in DNA damage assessed before and after a cancer diagnosis. Cancer Epidemiol Biomarkers Prev 17:990-994

Bonassi S, Abbondandolo A, Camurri L, Dal Pra L, De Ferrari M, Degrassi F, Forni A, Lamberti L, Lando C, Padovani P et al (1995) Are chromosome aberrations in circulating lymphocytes predictive of future cancer onset in humans? Preliminary results of an Italian cohort study. Cancer Genet Cytogenet 79:133-135

Bonassi S, Hagmar L, Stromberg U, Montagud AH, Tinnerberg H, Forni A, Heikkila P, Wanders S, Wilhardt P, Hansteen IL, Knudsen LE, Norppa H (2000) Chromosomal aberrations in lymphocytes predict human cancer independently of exposure to carcinogens. European Study Group on cytogenetic biomarkers and health. Cancer Res 60:1619-1625

Bonassi S, Norppa H, Ceppi M, Stromberg U, Vermeulen R, Znaor A, Cebulska-Wasilewska A, Fabianova E, Fucic A, Gundy S, Hansteen IL, Knudsen LE, Lazutka J, Rossner P, Sram RJ, Boffetta P (2008) Chromosomal aberration frequency in lymphocytes predicts the risk of cancer: results from a pooled cohort study of 22358 subjects in 11 countries. Carcinogenesis 29:1178-1183
Bristow RG, Ozcelik H, Jalali F, Chan N, Vesprini D (2007) Homologous recombination and prostate cancer: a model for novel DNA repair targets and therapies. Radiother Oncol 83:220-230

Brown LD, Zhao L (2002) A test for the Poisson distribution. The Indian J Statistics 64:611-625

Colleu-Durel S, Guitton N, Nourgalieva K, Legue F, Leveque J, Danic B, Chenal C (2004) Alkaline single-cell gel electrophoresis (comet assay): a simple technique to show genomic instability in sporadic breast cancer. Eur J Cancer 40:445-451

Dayal D, Martin SM, Limoli CL, Spitz DR (2008) Hydrogen peroxide mediates the radiation-induced mutator phenotype in mammalian cells. Biochem J 413:185-191

De Ruyck K, de Gelder V, Van Eijkeren M, Boterberg T, De Neve W, Vral A, Thierens H (2008) Chromosomal radiosensitivity in head and neck cancer patients: evidence for genetic predisposition? $\mathrm{Br}$ J Cancer 98:1723-1738

Dianov G, Bischoff C, Piotrowski J, Bohr VA (1998) Repair pathways for processing of 8-oxoguanine in DNA by mammalian cell extracts. J Biol Chem 273:33811-33816

Dotan ZA, Dotan A, Ramon J, Avivi L (2004) Altered mode of allelic replication accompanied by aneuploidy in peripheral blood lymphocytes of prostate cancer patients. Int J Cancer 111:60-66

El-Zein R, Gu Y, Sierra MS, Spitz MR, Strom SS (2005) Chromosomal instability in peripheral blood lymphocytes and risk of prostate cancer. Cancer Epidemiol Biomarkers Prev 14:748-752

Fan R, Kumaravel TS, Jalali F, Marrano P, Squire JA, Bristow RG (2004) Defective DNA strand break repair after DNA damage in prostate cancer cells: implications for genetic instability and prostate cancer progression. Cancer Res 64:8526-8533

Fenech M (2002) Chromosomal biomarkers of genomic instability relevant to cancer. Drug Discov Today 7:1128-1137

Frohlich DA, McCabe MT, Arnold RS, Day ML (2008) The role of $\mathrm{Nrf} 2$ in increased reactive oxygen species and DNA damage in prostate tumorigenesis. Oncogene 27:4353-4362

Hagmar L, Brogger A, Hansteen IL, Heim S, Hogstedt B, Knudsen L, Lambert B, Linnainmaa K, Mitelman F, Nordenson I et al (1994) Cancer risk in humans predicted by increased levels of chromosomal aberrations in lymphocytes: Nordic Study Group on the health risk of chromosome damage. Cancer Res 54:29192922

Hagmar L, Bonassi S, Stromberg U, Mikoczy Z, Lando C, Hansteen IL, Montagud AH, Knudsen L, Norppa H, Reuterwall C, Tinnerberg H, Brogger A, Forni A, Hogstedt B, Lambert B, Mitelman F, Nordenson I, Salomaa S, Skerfving S (1998) Cancer predictive value of cytogenetic markers used in occupational health surveillance programs. Recent Results Cancer Res 154:177-184

Heng HH, Bremer SW, Stevens J, Ye KJ, Miller F, Liu G, Ye CJ (2006) Cancer progression by non-clonal chromosome aberrations. J Cell Biochem 98:1424-1435

Hille A, Schmidberger H, Hermann RM, Christiansen H, Saile B, Pradier O, Hess CF (2005) A phase III randomized, placebocontrolled, double-blind study of misoprostol rectal suppositories to prevent acute radiation proctitis in patients with prostate cancer. Int J Radiat Oncol Biol Phys 63:1488-1493

Hille A, Schmidt-Giese E, Hermann RM, Herrmann MK, Rave-Frank M, Schirmer M, Christiansen H, Hess CF, Ramadori G (2008) A prospective study of faecal calprotectin and lactoferrin in the monitoring of acute radiation proctitis in prostate cancer treatment. Scand J Gastroenterol 43:52-58

Hsu TC (1983) Genetic instability in the human population: a working hypothesis. Hereditas 98:1-9

Iarmarcovai G, Ceppi M, Botta A, Orsiere T, Bonassi S (2008) Micronuclei frequency in peripheral blood lymphocytes of cancer patients: a meta-analysis. Mutat Res 659:274-283 
International Commission on Radiation Units and Measurements (1993) ICRU Report 50: prescribing, recording, and reporting photon beam therapy. International Commission on Radiation Units and Measurements, Washington DC

Jackson AL, Loeb LA (2001) The contribution of endogenous sources of DNA damage to the multiple mutations in cancer. Mutat Res 477:7-21

Khandrika L, Kumar B, Koul S, Maroni P, Koul HK (2009) Oxidative stress in prostate cancer. Cancer Lett 282(2):125-136

Kim GJ, Chandrasekaran K, Morgan WF (2006) Mitochondrial dysfunction, persistently elevated levels of reactive oxygen species and radiation-induced genomic instability: a review. Mutagenesis 21:361-367

Klein EA, Casey G, Silverman R (2006) Genetic susceptibility and oxidative stress in prostate cancer: integrated model with implications for prevention. Urology 68:1145-1151

Kolusayin Ozar MO, Orta T (2005) The use of chromosome aberrations in predicting breast cancer risk. J Exp Clin Cancer Res 24:217-222

Laurent A, Nicco C, Chereau C, Goulvestre C, Alexandre J, Alves A, Levy E, Goldwasser F, Panis Y, Soubrane O, Weill B, Batteux F (2005) Controlling tumor growth by modulating endogenous production of reactive oxygen species. Cancer Res 65:948-956

Lockett KL, Hall MC, Clark PE, Chuang SC, Robinson B, Lin HY, Su LJ, Hu JJ (2006) DNA damage levels in prostate cancer cases and controls. Carcinogenesis 27:1187-1193

Madhavi R, Guntur M, Ghosh R, Ghosh PK (1990) Double minute chromosomes in the leukocytes of a young girl with breast carcinoma. Cancer Genet Cytogenet 44:203-207

Mateuca RA, Roelants M, Iarmarcovai G, Aka PV, Godderis L, Tremp A, Bonassi S, Fenech M, Berge-Lefranc JL, KirschVolders M (2008) hOGG1(326), XRCC1(399) and XRCC3(241) polymorphisms influence micronucleus frequencies in human lymphocytes in vivo. Mutagenesis 23:35-41

Muller I, Geinitz H, Braselmann H, Baumgartner A, Fasan A, Thamm R, Molls M, Meineke V, Zitzelsberger H (2005) Time course of radiation-induced chromosomal aberrations in tumor patients after radiotherapy. Int J Radiat Oncol Biol Phys 63:1214-1220

Nohmi T, Kim SR, Yamada M (2005) Modulation of oxidative mutagenesis and carcinogenesis by polymorphic forms of human DNA repair enzymes. Mutat Res 591:60-73

Nordenson I, Beckman L, Liden S, Stjernberg N (1984) Chromosomal aberrations and cancer risk. Hum Hered 34:76-81

Ozen M, Hopwood VL, Balbay MD, Johnston DA, Babaian RJ, Logothetis CJ, von Eschenbach AC, Pathak S (2000) Correlation of non-random chromosomal aberrations in lymphocytes of prostate cancer patients with specific clinical parameters. Int $\mathbf{J}$ Oncol 17:113-117

Pero RW, Roush GC, Markowitz MM, Miller DG (1990) Oxidative stress, DNA repair, and cancer susceptibility. Cancer Detect Prev 14:555-561

Roberts SA, Spreadborough AR, Bulman B, Barber JB, Evans DG, Scott D (1999) Heritability of cellular radiosensitivity: a marker of low-penetrance predisposition genes in breast cancer? Am J Hum Genet 65:784-794

Rossner P, Boffetta P, Ceppi M, Bonassi S, Smerhovsky Z, Landa K, Juzova D, Sram RJ (2005) Chromosomal aberrations in lymphocytes of healthy subjects and risk of cancer. Environ Health Perspect 113:517-520

Rozalski R, Gackowski D, Roszkowski K, Foksinski M, Olinski R (2002) The level of 8-hydroxyguanine, a possible repair product of oxidative DNA damage, is higher in urine of cancer patients than in control subjects. Cancer Epidemiol Biomarkers Prev 11:1072-1075

Sandberg AA (1991) Chromosome abnormalities in human cancer and leukemia. Mutat Res 247:231-240
Schabath MB, Spitz MR, Grossman HB, Zhang K, Dinney CP, Zheng PJ, Wu X (2003) Genetic instability in bladder cancer assessed by the comet assay. J Natl Cancer Inst 95:540-547

Schmidberger H, Virsik-Koepp P, Rave-Frank M, Reinosch KR, Pradier O, Munzel U, Hess CF (2001) Reciprocal translocations in patients with testicular seminoma before and after radiotherapy. Int J Radiat Oncol Biol Phys 50:857-864

Scott D, Barber JB, Spreadborough AR, Burrill W, Roberts SA (1999) Increased chromosomal radiosensitivity in breast cancer patients: a comparison of two assays. Int J Radiat Biol 75:1-10

Sigurdson AJ, Doody MM, Rao RS, Freedman DM, Alexander BH, Hauptmann M, Mohan AK, Yoshinaga S, Hill DA, Tarone R, Mabuchi K, Ron E, Linet MS (2003) Cancer incidence in the US radiologic technologists health study, 1983-1998. Cancer 97:3080-3089

Sigurdson AJ, Hauptmann M, Alexander BH, Doody MM, Thomas CB, Struewing JP, Jones IM (2005) DNA damage among thyroid cancer and multiple cancer cases, controls, and long-lived individuals. Mutat Res 586:173-188

Smith TR, Miller MS, Lohman KK, Case LD, Hu JJ (2003) DNA damage and breast cancer risk. Carcinogenesis 24:883-889

Solomon E, Borrow J, Goddard AD (1991) Chromosome aberrations and cancer. Science 254:1153-1160

Steiner T, Junker K, Burkhardt F, Braunsdorf A, Janitzky V, Schubert $\mathrm{J}$ (2002) Gain in chromosome 8q correlates with early progression in hormonal treated prostate cancer. Eur Urol 41:167-171

Suzuki J, Inoue Y, Suzuki S (1995) Changes in the urinary excretion level of 8-hydroguanine by exposure to reactive oxygengenerating substances. Free Radic Biol Med 18:431-436

Trzeciak AR, Nyaga SG, Jaruga P, Lohani A, Dizdaroglu M, Evans MK (2004) Cellular repair of oxidatively induced DNA base lesions is defective in prostate cancer cell lines, PC-3 and DU145. Carcinogenesis 25:1359-1370

Tulard A, Hoffschir F, de Boisferon FH, Luccioni C, Bravard A (2003) Persistent oxidative stress after ionizing radiation is involved in inherited radiosensitivity. Free Radic Biol Med 35:68-77

Tzancheva M, Komitowski D (1997) Latent chromosomal instability in cancer patients. Hum Genet 99:47-51

Varga D, Michel I, Patino-Garcia B, Paiss T, Vogel W, Maier C (2005) Radiosensitivity detected by the micronucleus test is not generally increased in sporadic prostate cancer patients. Cytogenet Genome Res 111:41-45

Varga D, Hoegel J, Maier C, Jainta S, Hoehne M, Patino-Garcia B, Michel I, Schwarz-Boeger U, Kiechle M, Kreienberg R, Vogel $\mathrm{W}$ (2006) On the difference of micronucleus frequencies in peripheral blood lymphocytes between breast cancer patients and controls. Mutagenesis 21:313-320

Verhagen PC, Hermans KG, Brok MO, van Weerden WM, Tilanus MG, de Weger RA, Boon TA, Trapman J (2002) Deletion of chromosomal region $6 \mathrm{q} 14-16$ in prostate cancer. Int $\mathrm{J}$ Cancer 102:142-147

Waters DJ, Shen S, Xu H, Kengeri SS, Cooley DM, Chiang EC, Chen Y, Schlittler D, Oteham C, Combs GF Jr, Glickman LT, Morris JS, Bostwick DG (2007) Noninvasive prediction of prostatic DNA damage by oxidative stress challenge of peripheral blood lymphocytes. Cancer Epidemiol Biomarkers Prev 16:1906-1910

Wolter H, Trijic D, Gottfried HW, Mattfeldt T (2002) Chromosomal changes in incidental prostatic carcinomas detected by comparative genomic hybridization. Eur Urol 41:328-334

Wright EG (1999) Inherited and inducible chromosomal instability: a fragile bridge between genome integrity mechanisms and tumourigenesis. J Pathol 187:19-27 
Wu X, Spitz MR, Amos CI, Lin J, Shao L, Gu J, de Andrade M, Benowitz NL, Shields PG, Swan GE (2006) Mutagen sensitivity has high heritability: evidence from a twin study. Cancer Res 66:5993-5996

Wu X, Gu J, Spitz MR (2007) Mutagen sensitivity: a genetic predisposition factor for cancer. Cancer Res 67:3493-3495
Xuncla M, Barquinero JF, Caballin MR, Craven-Bartle J, Ribas M, de Vega JM, Barrios L (2008) Cytogenetic damage induced by radiotherapy. Evaluation of protection by amifostine and analysis of chromosome aberrations persistence. Int $\mathrm{J}$ Radiat Biol $84: 243-251$ 